
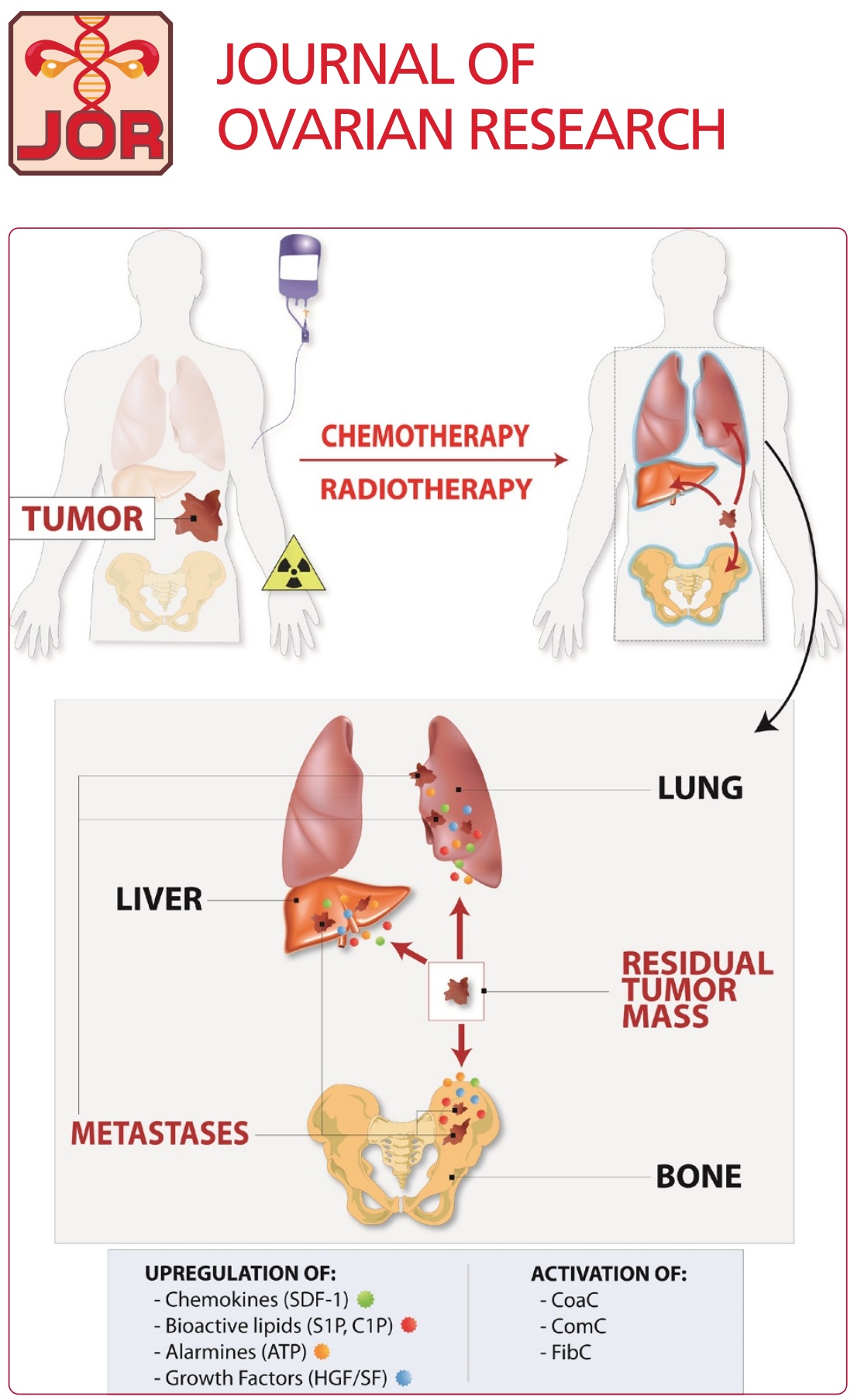

\title{
Induction of a tumor-metastasis-receptive microenvironment as an unwanted and underestimated side effect of treatment by chemotherapy or radiotherapy
}

Ratajczak et al. 


\title{
Induction of a tumor-metastasis-receptive microenvironment as an unwanted and underestimated side effect of treatment by chemotherapy or radiotherapy
}

\author{
Mariusz Z Ratajczak ${ }^{1 *}$, Tomasz Jadczyk², Gabriela Schneider ${ }^{1}$, Sham S Kakar ${ }^{1}$ and Magda Kucia ${ }^{1}$
}

\begin{abstract}
There are well-known side effects of chemotherapy and radiotherapy that are mainly related to the toxicity and impaired function of vital organs; however, the induction by these therapies of expression of several pro-metastatic factors in various tissues and organs that in toto create a pro-metastatic microenvironment is still, surprisingly, not widely acknowledged. In this review, we support the novel concept that toxic damage in various organs leads to upregulation in "bystander" tissues of several factors such as chemokines, growth factors, alarmines, and bioactive phosphosphingolipids, which attract circulating normal stem cells for regeneration but unfortunately also provide chemotactic signals to cancer cells that survived the initial treatment. We propose that this mechanism plays an important role in the metastasis of cancer cells to organs such as bones, lungs, and liver, which are highly susceptible to chemotherapeutic agents as well as ionizing irradiation. This problem indicates the need to develop efficient anti-metastatic drugs that will work in combination with, or follow, standard therapies in order to prevent the possibility of therapy-induced spread of tumor cells.
\end{abstract}

Keywords: Cancer metastasis, Side effects, Chemotherapy, Radiotherapy, SDF-1, CXCR4, S1P, C1P, Alarmines

\section{Introduction}

The results of conditioning strategies for bone marrow (BM) transplantation by employing myelo- or submyeloablative doses of chemotherapy or radiotherapy provides evidence that damage of the $\mathrm{BM}$ environment results in upregulation of several factors that direct chemottraction and homing of hematopoietic stem progenitor cells (HSPCs) to BM. The most important homing signal responsible for this effect is mediated by $\alpha$-chemokine stromal-derived factor 1 (SDF-1) [1,2]. The biological effect of this chemokine is supported by other factors, including bioactive phosphosphingolipids such as sphingosine-1phosphate (S1P) and ceramide-1-phosphate (C1P) [3-7], as well as some members of a family of alarmines, including extracellular nucleotides such as ATP and UTP $[8,9]$, that are released from damaged and "leaky" BM cells. All these

\footnotetext{
* Correspondence: mzrata01@louisville.edu

${ }^{1}$ Stem Cell Institute at the James Graham Brown Cancer Center, University of Louisville, 500 S. Floyd Street, Rm. 107, Louisville, KY 40202, USA

Full list of author information is available at the end of the article
}

factors direct migration and translocation of HSPCs circulating in peripheral blood (PB) into BM niches. Moreover, the same factors are known to be upregulated in organs damaged by hypoxia, as seen in acute myocardial infarction, stroke, ischemic kidney damage, or toxic liver injury, which chemoattract normal circulating stem cells for potential tissue/organ regeneration [10-14].

At the same time, all these factors are very well-known chemoattractants for several types of malignant cells and are involved in formation of distant metastases [15-20]. It is well known that metastases are responsible for more than $90 \%$ of tumor-associated mortality and thus are a crucial problem for developing more efficient and successful cancer therapies. Depending on the tumor type and microenvironment, as postulated 125 years ago by Paget in a famous "seed and soil hypothesis" [21,22], tumor cells have a preference for metastasizing to "tumor-receptive" organs. This receptiveness depends on a repertoire of chemoattractants secreted in a given tissue as well as expression of corresponding receptors on the surface of the 
circulating/migrating tumor cells. An important role is also played by tumor cell-expressed adhesion molecules that anchor circulating tumor cells to the endothelium at the site of the distant metastasis $[23,24]$.

One of the most important questions in oncology remains the true nature of the tumor cells that are endowed with migratory and thus metastatic properties. It is obvious that most growing tumors are composed of malignant cells that show different levels of maturation. Usually in a growing solid tumor, the more differentiated cells are seen in its central areas, and more primitive cells endowed with migratory/infiltration properties are encountered on the periphery [25].

According to accumulating evidence, the rarest tumor cells are cancer stem cells (CSCs), which are more resistant to treatment by standard therapies and, like most normal stem cells during embryogenesis, are strongly endowed with migratory properties [26-32]. Another possibility that has been postulated as a source of metastatic cancer cells is the epithelial-to-mesenchymal transition (EMT), in which some tumor cells, by changing their genetic program, become highly migratory cells [30,33-35]. Thus, as is currently speculated, both of these processes - the presence of CSCs in the growing tumor as well EMT - may drive tumor metastasis and are responsible for tumor dissemination to distant organs.

\section{Lessons from normal circulating stem cells during tissue/ organ injury}

One of the important features of early-development stem cells is their propensity to migrate, which is clearly seen for many types of stem cells during processes such as gastrulation and subsequent organ development [36-39]. Later on in adult life, some types of stem cells are still highly migratory and are mobilized into peripheral blood (PB) and lymph, migrating to distant locations $[40,41]$. The best examples for such stem cells are hematopoietic stem progenitor cells (HSPCs) [36,42], endothelial progenitor cells (EPCs) [43], mesenchymal stromal cells (MSCs) [44], and very small embryonic-like stem cells (VSELs) [45].

It is well known that all of these types of stem/progenitor cells are detectable under steady-state conditions in $\mathrm{PB}$ and lymph, and their number increases, for example, during organ damage or inflammation [46]. In all these situations, damaged tissues release potent chemotactic factors that direct trafficking of these cells. These prochemotactic compounds belong to families of chemokines, growth factors, bioactive lipids, and some small molecules known as alarmines [7-9,17]. Chemokines and some proangiopoietic growth factors are released from the damaged tissues in response to damage-related hypoxia involving hypoxia-inducible factor 1 alpha (HIF-1 $\alpha$ ) [47] activation of transcription of genes encoding chemokines (e.g., SDF-
1; interleukin 8, IL-8) [48-51] and selected growth factors (e.g., vascular endothelial growth factor, VEGF) that are primarily involved in promoting vascularization of damaged organs.

Also released from damaged cells during tissue/organ injury are so-called alarmines or damage-associated molecular pattern molecules (DAMPs, also known as danger-associated molecular pattern molecules), which can initiate and perpetuate immune responses and subsequent repair processes [52,53]. The most important molecules from this family of mediators are purine metabolites, including nucleotides (e.g., ATP and UTP) [54,55], the chromatin-associated protein high-mobility group box 1 (HMGB1) [56-58], and S100 molecules, which belong to a multigenic family of calcium-modulated proteins [59-61]. All these molecules are released from damaged cells and, after they have reached the extracellular space, serve as "danger" signals. Finally, accumulating evidence suggests a role for bioactive phosphosphingolipids such as S1P and $\mathrm{C} 1 \mathrm{P}$ in regulating trafficking of stem/progenitor cells. As we recently demonstrated, both S1P and C1P direct migration of HSPCs, MSCs, EPCs, and VSELs [7].

It is very likely that a proper repertoire of these factors upregulated in damaged tissues is important for mobilization into $\mathrm{PB}$ and subsequent homing to the damaged organs of specific subsets of circulating stem progenitor cells [62]. In support of this possibility, VEGF more selectively mobilizes EPCs into PB [63].

Release of normal stem cells into circulation and their subsequent homing into damaged tissues may play some role in regeneration of organs damaged by chemotherapy or radiotherapy. The beneficial effects of stem cells in regeneration of damaged tissues are mainly based on the paracrine effects of circulating stem cells [64-66] as well as some more direct effects such as for example their contribution to vasculogenesis [67].

\section{Circulating tumor cells}

Unfortunately, it is well known that, like normal stem cells, cancer cells also circulate in PB and lymph and may be seeded to distant tissues. Evidence has even accumulated that these circulating cancer cells may be already present at locations distant from the tumor at very early stages of tumor development [68]. As a population of de-differentiated and transformed normal cells, the propensity of tumor cells to migrate most likely reflects the migratory nature of normal earlydevelopment stem cells. This propensity may be particularly important for the population of most-primitive cancer cells present in the growing tumor known as CSCs $[26,27,29,32,69]$ or cancer cells endowed with migratory properties characteristic of mesenchymal cells generated in the process of EMT, which in consequence leads to formation of disseminating tumor cells (DTCs) [30,31]. 
Moreover, it is logical that circulating CSCs or DTCs respond to a similar repertoire of chemoattractants as normal cells circulating in PB. Extravasation of malignant cells to the sites of metastasis depends also on expression on their surface of adhesion molecules that may tether them to endothelium as well as expression of proteolytic enzymes such as various metalloproteinases (MMPs) that facilitate their migration and infiltration in the tissues [24,70,71]. Some evidence has accumulated that a metastasis-permissive microenvironment at a future site of metastasis has already been created some time before "arrival" of new unwanted inhabitants, CSCs or DTCs [61,72-74]. Moreover, it has even been also postulated that, in some cases, BM-derived cells are involved in induction of this pro-metastatic microenvironment at distant locations [61,72].

Therefore, despite significant reduction of tumor mass with initial treatment, some cancer cells more resistant to radiotherapy and chemotherapy (e.g., CSCs) may survive and after treatment respond to chemotactic cues induced by therapy at distant locations. It is well known that more primitive cells have a higher expression of drug efflux pumps [75-77], possess more efficient DNArepair mechanisms $[78,79]$, and are more resistant to hypoxia [47].

\section{Chemotherapy and radiotherapy create a pro-metastatic microenvironment in bone marrow and other tissues}

Besides surgical removal of tumor tissue, chemotherapy and radiotherapy are the most important and efficient treatment modalities employed to treat therapy-susceptible malignancies. The main aim of treatment - to destroy tumor cells - is unfortunately usually associated with toxicity to non-tumor cells and different degrees of tissue and organ damage. The organ most sensitive to toxic damage by chemotherapeutics is usually BM. Toxic damage to BM may somewhat mimic the situation encountered during conditioning before hematopoietic transplantation, when BM-residing cells are severely damaged and, in parallel, several chemoattractants are released in the BM microenvironment that play a role in chemoattraction and homing of the infused in the graft normal HSPCs $[1,2,46,80]$. We postulate that in a similar way, these factors may chemottract tumor cells that survived initial treatment.

In support of this notion, as already demonstrated by us and other groups, exposure of mice to irradiation [81], cyclophosphamide [80], or vincristine $[17,82]$ upregulates the levels of several chemokines and growth factors, such as SDF-1, HGF/SF, VEGF, and monocyte chemotactic protein-1 (MCP-1), in the BM microenvironment. In addition, as we have recently demonstrated, in vivo exposure of mice to irradiation and cyclophosphamide elevates BM expression of S1P and C1P, which are endowed with strong chemotactic properties against normal as well as malignant cells [7,17]. Exposure of BM to irradiation, similar as to chemotherapeutics, leads to release of several alarmines (e.g., ATP and UTP) from the damaged BM cells (manuscript in preparation). We can assume that a similar response accompanies the toxic effects of chemotherapy or radiotherapy in other sensitive organs, including liver and lungs.

All these pro-metastatic factors are released from the damaged tissues by different mechanisms. Accordingly, tissue damage-related hypoxia leads to synthesis and release of, for example, SDF-1, VEGF, and HGF/SF in an HIF-1 $\alpha$-dependent manner $[67,83]$. However, this process requires some time for these factors to be expressed through gene activation and transcription of mRNA and subsequent translation of mRNA into proteins. By contrast, alarmines or DAMPs (e.g., ATP, UTP, HMGB1, or S100 molecules) are released immediately from damaged and "leaky" cells $[56,61,72]$.

Furthermore, it is important to highlight that chemotherapy- or radiotherapy-associated tissue and organ damage also activates developmentally early proteolytic cascades, such as the complement cascade (ComC), coagulation cascade ( $\mathrm{CoaC})$, and fibrynolytic cascade (FibC). It is well known that some of the activated proteolytic cleavage products of these cascades, such as C3a, C5a, thrombin, urokinase or uPAR, are directly or indirectly involved in cancer metastasis [84-88].

An important mechanism related to chemotherapy- or radiotherapy-mediated activation of $\mathrm{CoaC}$ and $\mathrm{ComC}$ is activation of blood platelets and release of platelet-derived microvesicles [84,89-91]. These small circular membrane fragments may transfer several platelet-endothelium cell adhesion receptors, for example, glycoprotein IIb/IIIa (CD41), Ib, IaIIa, and P-selectin (CD62P), to the surface of circulating tumor cells and thus facilitate attachment of CSCs or DTCs to the endothelium at the site of a future metastasis [89,92].

In addition to this pro-metastatic, adhesion-mediated effect, it has been reported that some cytostatics e.g., cyclophosphamide, by exerting direct toxicity to the endothelial wall, which affects the integrity of the endothelial barrier, may facilitate seeding of cancer cells into damaged organs through the disrupted endothelium [80].

Figure 1 depicts our concept postulating creation of a chemotherapy- or radiotherapy-mediated pro-metastatic microenvironment in BM and other organs. This unwanted side effect is involved mainly in metastasis of tumor cells to tissues that are highly sensitive to damage by chemotheraputics as well as toxic doses of radiation (e.g., BM, liver, and lungs). Since BM tissue is highly sensitive to chemotherapy or radiotherapy, its damage facilitates creation of a metastasis-receptive microenvironment and is responsible for the occurrence of so frequent bone metastases as seen in the clinical setting. 


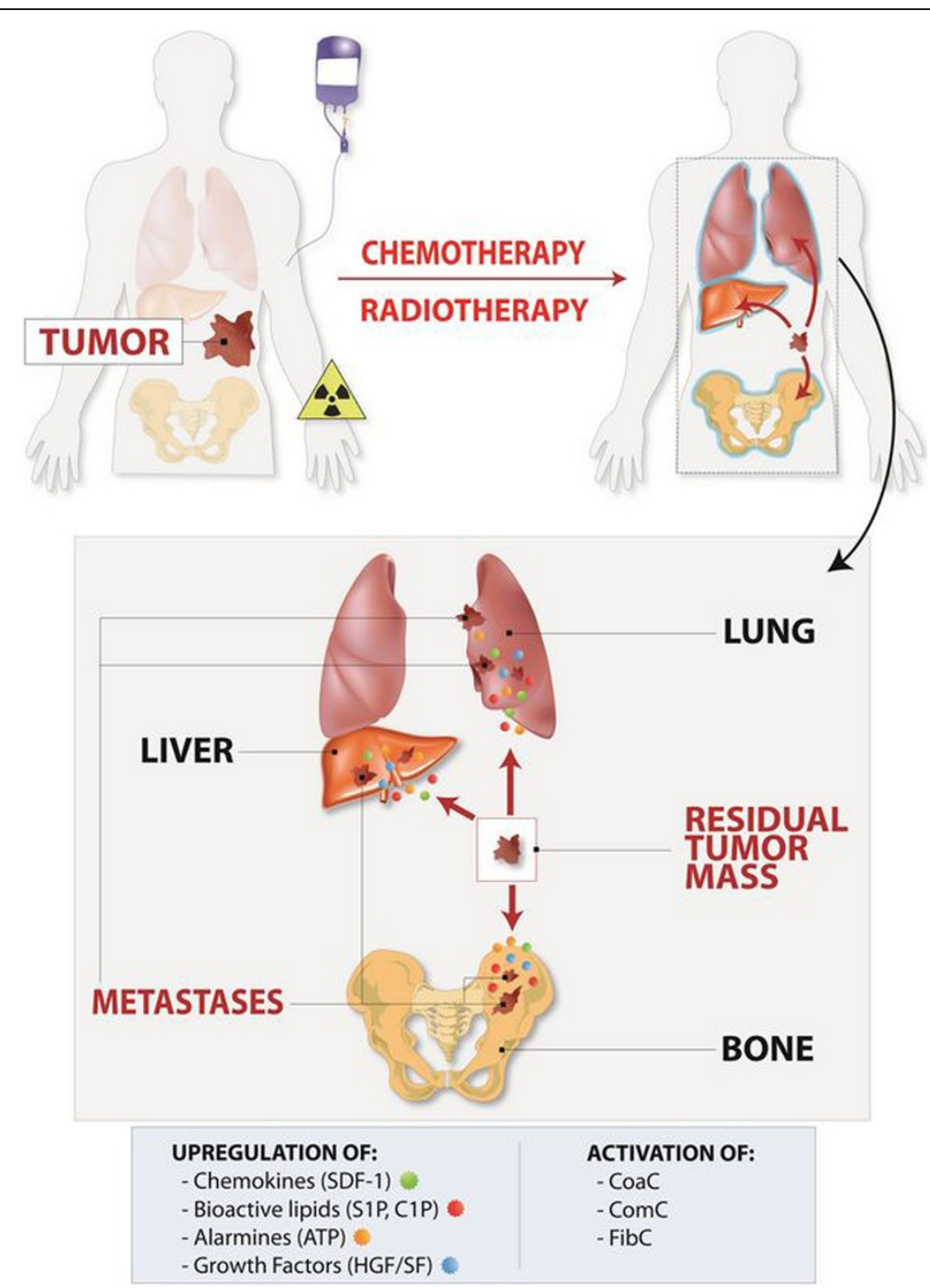

Figure 1 Chemotherapy or radiotherapy induces a metastasis-receptive microenvironment in various organs. One of the unwanted side effects of treatment is upregulation of several pro-metastatic and pro-survival factors, such as chemokines (e.g., SDF-1), growth factors (HGF/SF and VEGF), bioactive sphigophospholipids (S1P and C1P), and alarmines (ATP and UTP) in collateral-damaged tissues and organs. In parallel, in response to tissue damage, proteolytic cascades, such as the coagulation cascade (CoaC), complement cascade (ComC), and fibrynolytic cascade (FibC), are activated, which in different ways also enhance the metastasis of cancer cells that survived treatment. These most-resistant-to-therapy, and thus surviving, cancer cells are usually endowed with high endogenous motility. This mechanism plays an important role, primarily in metastasis of malignant cells to the tissues susceptible to the toxic effects of chemotherapy or radiotherapy, such as bones, lungs, liver and abdominal and pelvic cavities.

\section{Practical clinical implications and the need for new therapeutic approaches}

The natural propensity of CSCs or DTCs to migrate to distant metastasis-receptive locations and the fact that one of the unwanted side effects of chemotherapy or radiotherapy is induction of a metastasis-promoting microenvironment points to the important implication that standard treatment protocols should be followed by anti-metastatic strategies $[61,93,94]$. However, this is an obviously difficult task, because efficient anti-metastatic compounds are not currently available. One of the reasons for this unfortunate situation is that several developmental strategies for such drugs are based on targeting single chemoattractant-specific receptor axes (e.g., targeting SDF-1-CXCR4 or HGF/SF-c-Met). This is a somewhat questionable strategy, since tumor cells may respond simultaneously to several chemotactic factors and modulators of chemotactic responsiveness, and blockage of just one axis will be compensated by other unaffected pro-metastatic factors. The preferred sites of metastasis are tissues susceptible to damage by chemotherapy or radiotherapy such as bone marrow, and Figure 2 depicts a scenario where chemotherapy or radiotherapy induces a pro-metastatic microenvironment in bones for circulating CSCs or DTCs that survived treatment. 

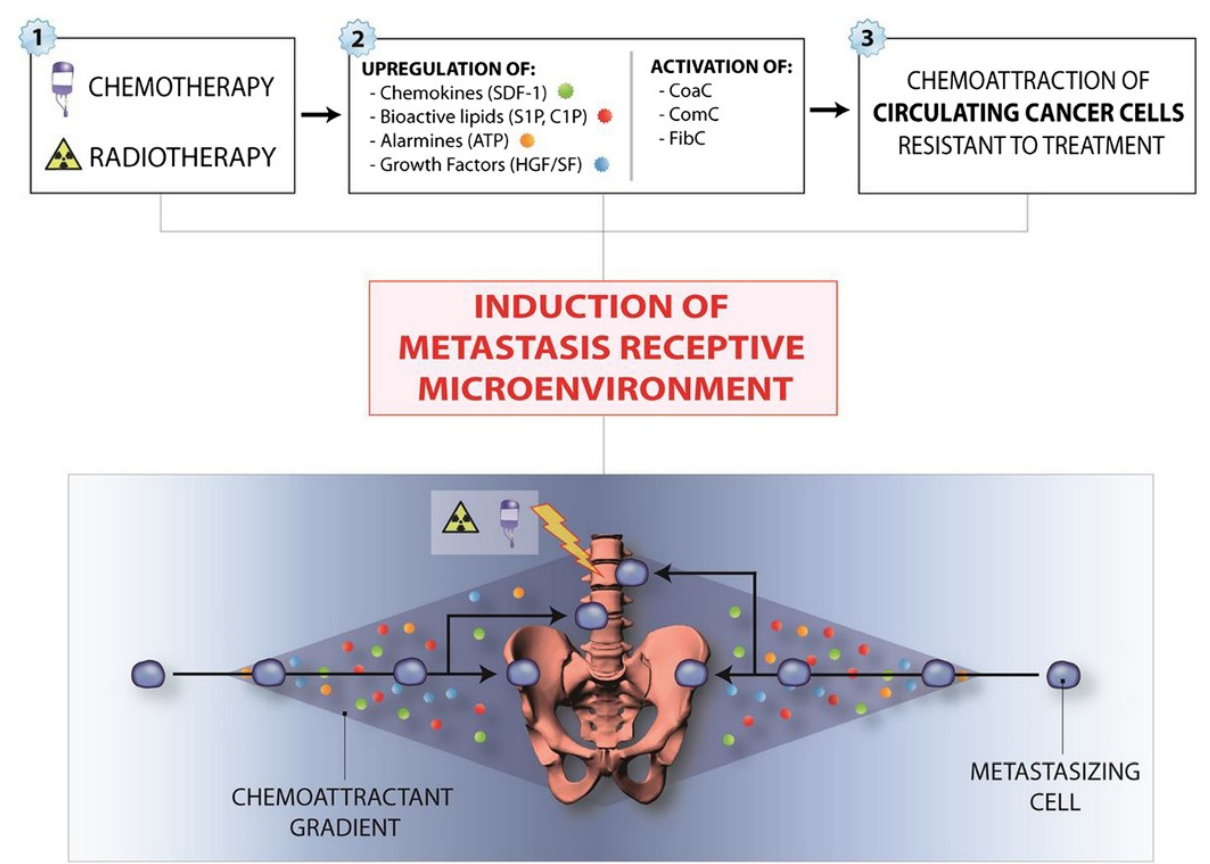

Figure 2 Chemotherapy- or radiotherapy-mediated metastasis of cancer cells to bones. Due to upregulation of several homing and pro-survival factors in response to BM microenvironment damage, circulating cancer cells may find a permissive environment in BM, which can originate growth of a bone metastasis. Similar mechanism may also operate in pelvic cavity after chemotherapy and lead to spread of ovarian cancer.

Nevertheless, in several well-controlled animal experimental models, it has been demonstrated that blockade of CXCR4 [50], CXCR7 [95], or c-Met [81] receptors by employing small molecular inhibitors; downregulation of these receptors by shRNA strategies [95]; in vivo administration of blocking antibodies against SDF-1 [50,61,96] or MCP-1 [80]; or application of S1P-binding aptamers [17] significantly diminished the process of chemotherapy- or radiotherapy-related dissemination of tumor cells to various organs.

However, the future of potent anti-metastatic drugs will depend on molecules that interfere with migration and adhesion processes of CSCs and DTCs downstream of surface receptors. It is obvious that the tumor specificity of such compounds will be a critical hurdle in development of such drugs. However, the simple and sad fact that metastases are responsible for $90 \%$ of cancerassociated mortalities points to the importance of developing such compounds for modern pharmacology.

\section{Implications for leukemia and lymphoma therapy}

However, while a major focus of this review is on solid tumors, which may metastasize and thus become unwanted inhabitants in BM or other organs, it is obvious that the same mechanisms may apply for malignant leukemia and lymphoma cells. As shown in Figure 3, both $\gamma$-irradiation as well as cyclophosphamide administration increase in BM expression of SDF-1, HGF/SF,
S1P, and C1P, which on the one hand are potent chemotactic factors for tumor cells and, on the other hand, are potent pro-survival and anti-apoptotic agents for a variety of normal and malignant cells, including leukemia and lymphoma cells $[3,17,80,81]$.

We propose that chemotherapy-induced BM toxicity may also have adverse effects on the most primitive leukemia or lymphoma stem cells. In response to treatment, the BM microenvironment releases several factors that may promote retention of malignant cells, and some of them involved in regeneration of marrow tissue may increase the survival of treatment-resistant cancer cells. To support this notion, it is well known that SDF-1, HGF/SF, S1P, and C1P are survival-increasing factors for many types of cells, including those from hematopoietic lineages [81,97].

Moreover, one of the treatment strategies in hematopoietic malignancies currently being explored is release of leukemia or lymphoma cells from the stem cell niches they occupy - by blocking the SDF-1-CXCR4 axis $[24,98,99]$ or by blocking other homing signals to render them more sensitive to chemotherapeutic agents. Unfortunately, the upregulation of homing factors in $\mathrm{BM}$ as result of chemotherapy may increase expression of homing signals and thus retention of the most primitive and therapyresistant cells in the $\mathrm{BM}$ microenvironment.

Leukemia and lymphoma CSCs and DTCs may also respond to homing cues in $\mathrm{BM}$ tissues of distant bones 

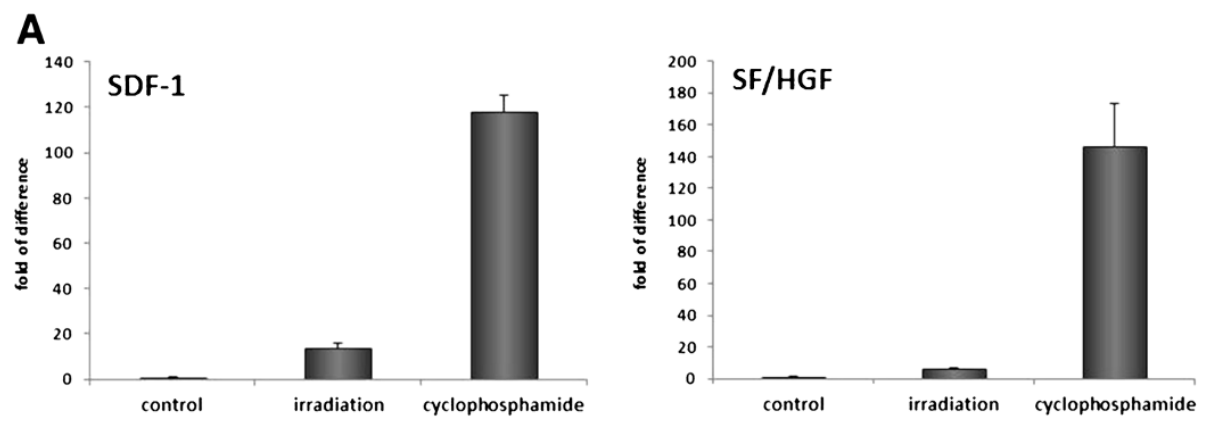

\section{B}
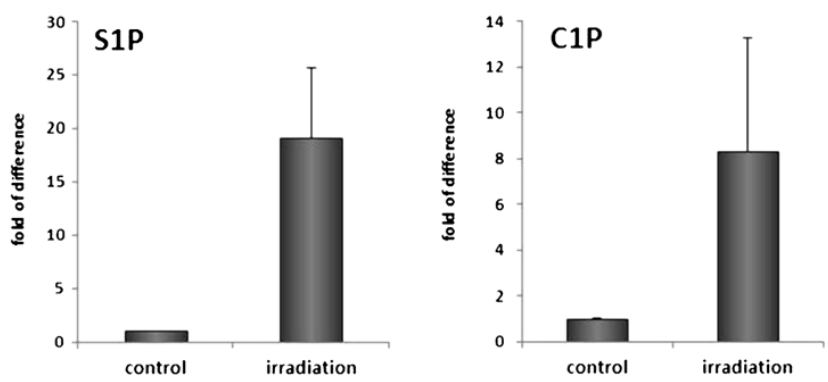

Figure 3 Increase in expression of important chemoattractants and pro-survival factors in BM after in vivo exposure to $\gamma$-irradiation or cyclophosphamide treatment. Panel A. Real-time PCR analysis of changes in the expression of mRNA for SDF-1 and SF in murine BM 24 hours after irradiation (750 cGy) or exposure to cyclophosphamide ( $200 \mathrm{mg} / \mathrm{kg} / \mathrm{bw} / \mathrm{mouse})$. The experiment was repeated three times with four animals/group. Panel B. Mass spectrometry analysis shows that ceramide-1-phosphate (C1P) and sphingosine-1-phosphate (S1P) become upregulated in murine BM after conditioning for hematopoietic transplantation by lethal irradiation [17]. The data shown in panels A-B represent the combined results from three independent experiments carried out in triplicate per group.

as well as migrate to organs where they find a permissive microenvironment (e.g., spleen, lymph nodes, and liver). This may, with time, promote spread of the malignancy.

\section{Implications for ovarian cancer metastasis and therapy}

Ovarian cancer has the highest mortality rate among all the gynecologic tumors and in contrast to many other hematogenously metastasizing solid tumors disseminate within the peritoneal cavity [100]. It is often diagnosed at a late stage after tumor cells are already disseminated within pelvis. Thus, patients with ovarian cancer usually have at time of diagnosis locally advanced disease in the pelvic cavity, with continuous extension to uterus, fallopian tube, and the sigmoid colon. In contrast to prostate cancer, ovarian cancer in rare cases only metastasizes to BM or brain. It is also a chemotherapy sensitive malignancy. Therefore, radiotherapy is not a common option for its treatment.

Several genes, growth factors, adhesion molecules, chemokines, metalloproteinases and hormones have been reported to play critical role in progression and metastasis of ovarian cancer [100]. Many of them such as SDF-1, HGF/SF or S1P may be upregulated in tumor cells and microenvironment (e.g., ascites) in response to chemo/ radiotherapy (Figure 1) [98-108].

As reported, SDF-1induces rapid intracellular calcium mobilization and activation of metalloproteinases MMP-
2 and MMP-9 which enhance ERK1/2 signaling pathway leading to increase of cancer cell adhesion. SDF-1 also increases expression of CXCR4 at both the transcription and protein levels [102,106]. HGF/SF is another prometastatic factor that may be upregulated by chemo/ radiotherapy, which after binding to tyrosine kinase receptor c-Met activates mitogenic pathways and thus plays an important role in tumor growth. Overexpression of HGF/SF or c-Met in ovarian cancer cells increases expression of $\alpha 5$ and $\beta 1$ integrins, urokinase and metalloproteinases (MMP-2 and MMP-9) that have been shown to increase tumor growth and metastasis [103]. In addition HGF/SF activates also MAPKp42/44 and PI3K which leads to dissemination of ovarian cells [103,104]. In addition, HGF functions in morphological remodeling, invasion and migration of cancer cells, and decreases the expression of E-cadherin, $\beta$-catenin, and caveolin-1 at the cell membrane, mechanisms essential in promoting metastasis [106-108]. Finally, evidence accumulated that S1P signaling is also involved in epithelial ovarian tumorigenesis. This bioactive lipid is elevated in human ascites [105] and stimulates migration and invasion of ovarian epithelial cancer cells (EOC).

All this supports a concept that treatment of ovarian cancer should be from beginning combined with antimetastatic approaches to lower risk of metastatic side 
effects of chemo/radiotherapy. It would also be interesting to investigate if so called metronomic chemotherapy, based in contrast to traditional chemotherapy on chronic, equally spaced administration of low doses of various chemotherapeutic drugs without extended rest periods that results in lower rate of metastasis/recurrence [109], is associated with reduced release of prometastatic factors from damaged organs.

\section{Conclusions}

We propose a novel concept whereby the unwanted and underappreciated side effects of chemotherapy or radiotherapy create a metastasis-receptive microenvironment in bones as well as in other organs of the body (e.g., pelvic cavity). Upregulation of several chemokines, growth factors, alarmines, bioactive phosphosphingolipids as well as activation of $\mathrm{CoaC}, \mathrm{ComS}$, FibC and metalloproteinases, in toto, enhances and modulates trafficking and survival of CSCs and DTCs that survived treatment. This implies a challenge for modern pharmacology to develop powerful anti-metastatic compounds that can be combined with standard chemotherapy and radiotherapy protocols or applied as a follow up to these protocols.

\section{Competing interests}

The authors declare that they have no competing interests.

\section{Authors' contributions}

MZR - conceived idea and wrote paper SSK - reviewed and approved manuscript MK - referenced mansucript TJ - prepared Figures 1 and 2 GS - approved and approved manuscript, prepared Figure 3. All authors read and approved the final manuscript.

\section{Acknowledgements}

This work was supported by NIH grant 2R01 DK074720, NIH grant 1R01HL112788, the Stella and Henry Hoenig Endowment, and grant Maestro 2011/02/A/NZ4/00035 to MZR.

\section{Author details}

'Stem Cell Institute at the James Graham Brown Cancer Center, University of Louisville, 500 S. Floyd Street, Rm. 107, Louisville, KY 40202, USA. ${ }^{2}$ Third

Division of Cardiology, Silesian Medical University, Katowice, Poland.

Received: 2 December 2013 Accepted: 26 December 2013

Published: 27 December 2013

\section{References}

1. Peled A, Kollet O, Ponomaryov T, Petit I, Franitza S, Grabovsky V, et al: The chemokine SDF-1 activates the integrins LFA-1, VLA-4, and VLA-5 on immature human $\mathrm{CD} 34(+)$ cells: role in transendothelial/stromal migration and engraftment of NOD/SCID mice. Blood 2000, 95:3289-3296.

2. Papayannopoulou T: Bone marrow homing: the players, the playfield, and their evolving roles. Curr Opin Hematol 2003, 10:214-219.

3. Ratajczak MZ, Lee H, Wysoczynski M, Wan W, Marlicz W, Laughlin MJ, et al: Novel insight into stem cell mobilization-plasma sphingosine-1-phosphate is a major chemoattractant that directs the egress of hematopoietic stem progenitor cells from the bone marrow and its level in peripheral blood increases during mobilization due to activation of complement cascade/ membrane attack complex. Leukemia 2010, 24:976-985.

4. Granado MH, Gangoiti P, Ouro A, Arana L, Gonzalez M, Trueba M, et al: Ceramide 1-phosphate (C1P) promotes cell migration Involvement of a specific C1P receptor. Cell Signal 2009, 21:405-412.
5. Pappu R, Schwab SR, Cornelissen I, Pereira JP, Regard JB, Xu Y, et al: Promotion of lymphocyte egress into blood and lymph by distinct sources of sphingosine-1-phosphate. Science 2007, 316:295-298.

6. Seitz G, Boehmler AM, Kanz L, Mohle R: The role of sphingosine 1-phosphate receptors in the trafficking of hematopoietic progenitor cells. Ann N Y Acad Sci 2005, 1044:84-89.

7. Kim C, Schneider G, Abdel-Latif A, Mierzejewska K, Sunkara M, Borkowska S, et al: Ceramide-1-phosphate regulates migration of multipotent stromal cells and endothelial progenitor cells-implications for tissue regeneration. Stem Cells 2013, 31:500-510.

8. Ulrich $\mathrm{H}$, Abbracchio MP, Burnstock G: Extrinsic purinergic regulation of neural stem/progenitor cells: implications for CNS development and repair. Stem Cell Rev 2012, 8:755-767.

9. Rossi L, Manfredini R, Bertolini F, Ferrari D, Fogli M, Zini R, et al: The extracellular nucleotide UTP is a potent inducer of hematopoietic stem cell migration. Blood 2007, 109:533-542.

10. Ratajczak MZ, Kucia M, Reca R, Majka M, Janowska-Wieczorek A, Ratajczak J: Stem cell plasticity revisited: CXCR4-positive cells expressing mRNA for early muscle, liver and neural cells 'hide out' in the bone marrow. Leukemia 2004, 18:29-40.

11. Wojakowski W, Landmesser U, Bachowski R, Jadczyk T, Tendera M: Mobilization of stem and progenitor cells in cardiovascular diseases. Leukemia 2012, 26:23-33.

12. Paczkowska E, Kucia M, Koziarska D, Halasa M, Safranow K, Masiuk M, et al: Clinical evidence that very small embryonic-like stem cells are mobilized into peripheral blood in patients after stroke. Stroke 2009 40:1237-1244.

13. Camussi G, Deregibus MC, Tetta C: Paracrine/endocrine mechanism of stem cells on kidney repair: role of microvesicle-mediated transfer of genetic information. Curr Opin Nephrol Hypertens 2010, 19:7-12.

14. Golan K, Vagima Y, Ludin A, Itkin T, Cohen-Gur S, Kalinkovich A, et al: S1P promotes murine progenitor cell egress and mobilization via S1P1mediated ROS signaling and SDF-1 release. Blood 2012, 119:2478-2488.

15. Hsu A, Zhang W, Lee JF, An J, Ekambaram P, Liu J, et al: Sphingosine-1phosphate receptor-3 signaling up-regulates epidermal growth factor receptor and enhances epidermal growth factor receptor-mediated carcinogenic activities in cultured lung adenocarcinoma cells. Int J Oncol 2012, 40:1619-1626.

16. Kim ES, Kim JS, Kim SG, Hwang S, Lee CH, Moon A: Sphingosine 1-phosphate regulates matrix metalloproteinase-9 expression and breast cell invasion through S1P3-Galphaq coupling. J Cell Sci 2011, 124:2220-2230.

17. Schneider G, Bryndza E, Abdel-Latif A, Ratajczak J, Maj M, Tarnowski M, et al: Bioactive lipids S1P and C1P are prometastatic factors in human rhabdomyosarcoma, and their tissue levels increase in response to radio/chemotherapy. Mol Cancer Res 2013, 11:793-807.

18. Heffernan-Stroud LA, Obeid LM: Sphingosine kinase 1 in cancer. Adv Cancer Res 2013, 117:201-235.

19. Muller A, Homey B, Soto H, Ge N, Catron D, Buchanan ME, et al: Involvement of chemokine receptors in breast cancer metastasis. Nature 2001, 410:50-56.

20. Wang J, Loberg R, Taichman RS: The pivotal role of CXCL12 (SDF-1)/ CXCR4 axis in bone metastasis. Cancer Metastasis Rev 2006, 25:573-587.

21. Paget S: The distribution of secondary growths in cancer of the breast. Lancet 1889, 1:98-101.

22. Paget $\mathrm{S}$ : The distribution of secondary growths in cancer of the breast. 1889. Cancer Metastasis Rev 1989, 8:98-101.

23. Chambers AF, Groom AC, MacDonald IC: Dissemination and growth of cancer cells in metastatic sites. Nat Rev Cancer 2002, 2:563-572.

24. Kaplan RN, Riba RD, Zacharoulis S, Bramley AH, Vincent L, Costa C, et al: VEGFR1-positive haematopoietic bone marrow progenitors initiate the pre-metastatic niche. Nature 2005, 438:820-827

25. Brabletz T, Jung A, Reu S, Porzner M, Hlubek F, Kunz-Schughart LA, et al: Variable beta-catenin expression in colorectal cancers indicates tumor progression driven by the tumor environment. Proc Natl Acad Sci U S A 2001, 98:10356-10361.

26. Lapidot T, Sirard C, Vormoor J, Murdoch B, Hoang T, Caceres-Cortes J, et al A cell initiating human acute myeloid leukaemia after transplantation into SCID mice. Nature 1994, 367:645-648.

27. Al-Hajj M, Wicha MS, Benito-Hernandez A, Morrison SJ, Clarke MF: Prospective identification of tumorigenic breast cancer cells. Proc Natl Acad Sci U S A 2003, 100:3983-3988 
28. Fang D, Nguyen TK, Leishear K, Finko R, Kulp AN, Hotz S, et al: A tumorigenic subpopulation with stem cell properties in melanomas. Cancer Res 2005, 65:9328-9337

29. Bonnet D, Dick JE: Human acute myeloid leukemia is organized as a hierarchy that originates from a primitive hematopoietic cell. Nat Med 1997, 3:730-737

30. Mani SA, Guo W, Liao MJ, Eaton EN, Ayyanan A, Zhou AY, et al: The epithelial-mesenchymal transition generates cells with properties of stem cells. Cell 2008, 133:704-715.

31. Morel AP, Lievre M, Thomas C, Hinkal G, Ansieau S, Puisieux A: Generation of breast cancer stem cells through epithelial-mesenchymal transition. PLoS One 2008, 3:e2888.

32. Singh SK, Hawkins C, Clarke ID, Squire JA, Bayani J, Hide T, et al: Identification of human brain tumour initiating cells. Nature 2004, 432:396-401.

33. Maddaluno L, Rudini N, Cuttano R, Bravi L, Giampietro C, Corada M, et al: EndMT contributes to the onset and progression of cerebral cavernous malformations. Nature 2013, 498:492-496

34. White RA, Neiman JM, Reddi A, Han G, Birlea S, Mitra D, et al: Epithelia stem cell mutations that promote squamous cell carcinoma metastasis. J Clin Invest 2013, 123:4390-4404.

35. Thiery JP, Acloque H, Huang RY, Nieto MA: Epithelial-mesenchymal transitions in development and disease. Cell 2009, 139:871-890.

36. Ara T, Tokoyoda K, Sugiyama T, Egawa T, Kawabata K, Nagasawa T: Long-term hematopoietic stem cells require stromal cell-derived factor- 1 for colonizing bone marrow during ontogeny. Immunity 2003, 19:257-267.

37. Anderson R, Copeland TK, Scholer H, Heasman J, Wylie C: The onset of germ cell migration in the mouse embryo. Mech Dev 2000, 91:61-68.

38. Molyneaux KA, Zinszner H, Kunwar PS, Schaible K, Stebler J, Sunshine MJ et al: The chemokine SDF1/CXCL12 and its receptor CXCR4 regulate mouse germ cell migration and survival. Development 2003, 130:4279-4286.

39. Christensen JL, Wright DE, Wagers AJ, Weissman IL: Circulation and chemotaxis of fetal hematopoietic stem cells. PLoS Biol 2004, 2:E75.

40. Bonig H, Papayannopoulou T: Hematopoietic stem cell mobilization: updated conceptual renditions. Leukemia 2013, 27:24-31.

41. Greenbaum AM, Link DC: Mechanisms of G-CSF-mediated hematopoietic stem and progenitor mobilization. Leukemia 2011, 25:211-217.

42. Levesque JP, Helwani FM, Winkler IG: The endosteal 'osteoblastic' niche and its role in hematopoietic stem cell homing and mobilization. Leukemia 2010, 24:1979-1992.

43. Cesselli D, Beltrami AP, Rigo S, Bergamin N, D'Aurizio F, Verardo R, et al: Multipotent progenitor cells are present in human peripheral blood. Circ Res 2009, 104:1225-1234.

44. Brouard N, Driessen R, Short B, Simmons PJ: G-CSF increases mesenchyma precursor cell numbers in the bone marrow via an indirect mechanism involving osteoclast-mediated bone resorption. Stem Cell Res 2010, 5:65-75.

45. Kucia MJ, Wysoczynski M, Wu W, Zuba-Surma EK, Ratajczak J, Ratajczak MZ Evidence that very small embryonic-like stem cells are mobilized into peripheral blood. Stem Cells 2008, 26:2083-2092

46. Kucia M, Reca R, Miekus K, Wanzeck J, Wojakowski W, Janowska-Wieczorek $A$, et al: Trafficking of normal stem cells and metastasis of cancer stem cells involve similar mechanisms: pivotal role of the SDF-1-CXCR4 axis. Stem Cells 2005, 23:879-894.

47. Du R, Lu KV, Petritsch C, Liu P, Ganss R, Passegue E, et al: HIF1alpha induces the recruitment of bone marrow-derived vascular modulatory cells to regulate tumor angiogenesis and invasion. Cancer Cell 2008, 13:206-220.

48. Ceradini DJ, Kulkarni AR, Callaghan MJ, Tepper OM, Bastidas N, Kleinman $M E$, et al: Progenitor cell trafficking is regulated by hypoxic gradients through HIF-1 induction of SDF-1. Nat Med 2004, 10:858-864.

49. Wysoczynski M, Shin DM, Kucia M, Ratajczak MZ: Selective upregulation of interleukin- 8 by human rhabdomyosarcomas in response to hypoxia: therapeutic implications. Int J Cancer 2010, 126:371-381.

50. Libura J, Drukala J, Majka M, Tomescu O, Navenot JM, Kucia M, et al: CXCR4-SDF-1 signaling is active in rhabdomyosarcoma cells and regulates locomotion, chemotaxis, and adhesion. Blood 2002, 100:2597-2606.

51. Ponomaryov T, Peled A, Petit I, Taichman RS, Habler L, Sandbank J, et al: Induction of the chemokine stromal-derived factor-1 following DNA damage improves human stem cell function. J Clin Invest 2000, 106:1331-1339.
52. Nace G, Evankovich J, Eid R, Tsung A: Dendritic cells and damage-associated molecular patterns: endogenous danger signals linking innate and adaptive immunity. J Innate Immun 2012, 4:6-15.

53. Srikrishna G, Freeze HH: Endogenous damage-associated molecular pattern molecules at the crossroads of inflammation and cancer. Neoplasia 2009, 11:615-628.

54. Ratajczak MZ, Kim C, Ratajczak J, Janowska-Wieczorek A: Innate immunity as orchestrator of bone marrow homing for hematopoietic stem/progenitor cells. Adv Exp Med Biol 2013, 735:219-232.

55. Morrone FB, Jacques-Silva MC, Horn AP, Bernardi A, Schwartsmann G, Rodnight $R$, et al: Extracellular nucleotides and nucleosides induce proliferation and increase nucleoside transport in human glioma cell lines. J Neurooncol 2003, 64:211-218.

56. Bianchi ME, Manfredi AA: High-mobility group box 1 (HMGB1) protein at the crossroads between innate and adaptive immunity. Immunol Rev 2007, 220:35-46.

57. Wang $\mathrm{H}$, Bloom O, Zhang M, Vishnubhakat JM, Ombrellino M, Che J, et al: HMG-1 as a late mediator of endotoxin lethality in mice. Science 1999, 285:248-251.

58. Chavakis E, Hain A, Vinci M, Carmona G, Bianchi ME, Vajkoczy P, et al: High-mobility group box 1 activates integrin-dependent homing of endothelial progenitor cells. Circ Res 2007, 100:204-212.

59. Metting Z, Wilczak N, Rodiger LA, Schaaf J, Mvan der Naalt J: GFAP and $\mathrm{S} 100 \mathrm{~B}$ in the acute phase of mild traumatic brain injury. Neurology 2012 78:1428-1433.

60. Kwon CH, Moon HJ, Park HJ, Choi JH, Park do Y: S100A8 and S100A9 promotes invasion and migration through p38 mitogen-activated protein kinase-dependent NF-kappaB activation in gastric cancer cells. Mol Cells 2013, 35:226-234.

61. Hiratsuka S, Watanabe A, Aburatani H, Maru Y: Tumour-mediated upregulation of chemoattractants and recruitment of myeloid cells predetermines lung metastasis. Nat Cell Biol 2006, 8:1369-1375.

62. Doan PL, Chute JP: The vascular niche: home for normal and malignant hematopoietic stem cells. Leukemia 2012, 26:54-62.

63. Pitchford SC, Furze RC, Jones CP, Wengner AM, Rankin SM: Differential mobilization of subsets of progenitor cells from the bone marrow. Cell Stem Cell 2009, 4:62-72.

64. Ratajczak MZ, Kucia M, Jadczyk T, Greco NJ, Wojakowski W, Tendera M, et al: Pivotal role of paracrine effects in stem cell therapies in regenerative medicine: can we translate stem cell-secreted paracrine factors and microvesicles into better therapeutic strategies? Leukemia 2012, 26:1166-1173.

65. Majka M, Janowska-Wieczorek A, Ratajczak J, Ehrenman K, Pietrzkowski Z, Kowalska MA, et al: Numerous growth factors, cytokines, and chemokines are secreted by human CD34(+) cells, myeloblasts, erythroblasts, and megakaryoblasts and regulate normal hematopoiesis in an autocrine/ paracrine manner. Blood 2001, 97:3075-3085.

66. Sahoo S, Klychko E, Thorne T, Misener S, Schultz KM, Millay M, et al: Exosomes from human $\mathrm{CD} 34(+)$ stem cells mediate their proangiogenic paracrine activity. Circ Res 2011, 109:724-728.

67. Ceradini DJ, Gurtner GC: Homing to hypoxia: HIF-1 as a mediator of progenitor cell recruitment to injured tissue. Trends Cardiovasc Med 2005, 15:57-63.

68. Stoecklein $\mathrm{NH}$, Hosch SB, Bezler M, Stern F, Hartmann $\mathrm{CH}$, Vay $\mathrm{C}$, et al: Direct genetic analysis of single disseminated cancer cells for prediction of outcome and therapy selection in esophageal cancer. Cancer Cell 2008, 13:441-453.

69. Welm B, Behbod F, Goodell MA, Rosen JM: Isolation and characterization of functional mammary gland stem cells. Cell Prolif 2003, 36(Suppl 1):17-32.

70. Janowska-Wieczorek A, Marquez-Curtis LA, Wysoczynski M, Ratajczak MZ: Enhancing effect of platelet-derived microvesicles on the invasive potential of breast cancer cells. Transfusion 2006, 46:1199-1209.

71. Hiratsuka S, Nakamura K, Iwai S, Murakami M, Itoh T, Kijima H, et al: MMP9 induction by vascular endothelial growth factor receptor-1 is involved in lung-specific metastasis. Cancer Cell 2002, 2:289-300.

72. Rafii S, Lyden D: S100 chemokines mediate bookmarking of premetastatic niches. Nat Cell Biol 2006, 8:1321-1323.

73. Barcellos-Hoff MH, Lyden D, Wang TC: The evolution of the cancer niche during multistage carcinogenesis. Nat Rev Cancer 2013, 13:511-518.

74. Sceneay J, Smyth MJ, Moller A: The pre-metastatic niche: finding common ground. Cancer Metastasis Rev 2013, 32:449-464. 
75. Moitra K, Lou H, Dean M: Multidrug efflux pumps and cancer stem cells: insights into multidrug resistance and therapeutic development. Clin Pharmacol Ther 2011, 89:491-502.

76. Hirschmann-Jax C, Foster AE, Wulf GG, Nuchtern JG, Jax TW, Gobel U, et al: A distinct "side population" of cells with high drug efflux capacity in human tumor cells. Proc Natl Acad Sci U S A 2004, 101:14228-14233.

77. Scharenberg CW, Harkey MA, Torok-Storb B: The ABCG2 transporter is an efficient Hoechst 33342 efflux pump and is preferentially expressed by immature human hematopoietic progenitors. Blood 2002, 99:507-512.

78. Lord CJ, Ashworth A: Mechanisms of resistance to therapies targeting BRCA-mutant cancers. Nat Med 2013, 19:1381-1388.

79. Landi S, Gemignani F, Canzian F, Gaborieau V, Barale R, Landi D, et al: DNA repair and cell cycle control genes and the risk of young-onset lung cancer. Cancer Res 2006, 66:11062-11069.

80. Park SI, Liao J, Berry JE, Li X, Koh AJ, Michalski ME, et al: Cyclophosphamide creates a receptive microenvironment for prostate cancer skeletal metastasis. Cancer Res 2012, 72:2522-2532.

81. Jankowski K, Kucia M, Wysoczynski M, Reca R, Zhao D, Trzyna E, et al: Both hepatocyte growth factor (HGF) and stromal-derived factor-1 regulate the metastatic behavior of human rhabdomyosarcoma cells, but only HGF enhances their resistance to radiochemotherapy. Cancer Res 2003, 63:7926-7935.

82. Parameswaran R, Yu M, Lim M, Groffen J, Heisterkamp N: Combination of drug therapy in acute lymphoblastic leukemia with a CXCR4 antagonist. Leukemia 2011, 25:1314-1323.

83. Youn SW, Lee SW, Lee J, Jeong HK, Suh JW, Yoon CH, et al: COMP-Ang1 stimulates HIF-1alpha-mediated SDF-1 overexpression and recovers ischemic injury through BM-derived progenitor cell recruitment. Blood 2011, 117:4376-4386.

84. Wysoczynski M, Liu R, Kucia M, Drukala J, Ratajczak MZ: Thrombin regulates the metastatic potential of human rhabdomyosarcoma cells: distinct role of PAR1 and PAR3 signaling. Mol Cancer Res 2010, 8:677-690.

85. Hu L, Lee M, Campbell W, Perez-Soler R, Karpatkin S: Role of endogenous thrombin in tumor implantation, seeding, and spontaneous metastasis. Blood 2004, 104:2746-2751

86. Shi X, Gangadharan B, Brass LF, Ruf W, Mueller BM: Protease-activated receptors (PAR1 and PAR2) contribute to tumor cell motility and metastasis. Mol Cancer Res 2004, 2:395-402.

87. LeBeau AM, Duriseti S, Murphy ST, Pepin F, Hann B, Gray JW, et al: Targeting UPAR with antagonistic recombinant human antibodies in aggressive breast cancer. Cancer Res 2013, 73:2070-2081.

88. Goncalves A, Esterni B, Bertucci F, Sauvan R, Chabannon C, Cubizolles M, et al: Postoperative serum proteomic profiles may predict metastatic relapse in high-risk primary breast cancer patients receiving adjuvant chemotherapy. Oncogene 2006, 25:981-989.

89. Janowska-Wieczorek A, Wysoczynski M, Kijowski J, Marquez-Curtis L, Machalinski B, Ratajczak J, et al: Microvesicles derived from activated platelets induce metastasis and angiogenesis in lung cancer. Int J Cancer 2005, 113:752-760.

90. Wysoczynski M, Ratajczak MZ: Lung cancer secreted microvesicles: underappreciated modulators of microenvironment in expanding tumors. Int J Cancer 2009, 125:1595-1603.

91. Ratajczak MZ, Kim CH, Wojakowski W, Janowska-Wieczorek A, Kucia M, Ratajczak J: Innate immunity as orchestrator of stem cell mobilization. Leukemia 2010, 24:1667-1675.

92. Scholz T, Temmler U, Krause S, Heptinstall S, Losche W: Transfer of tissue factor from platelets to monocytes: role of platelet-derived microvesicles and CD62P. Thromb Haemost 2002, 88:1033-1038.

93. Joyce JA, Pollard JW: Microenvironmental regulation of metastasis. Nat Rev Cancer 2009, 9:239-252.

94. Jung Y, Kim JK, Shiozawa Y, Wang J, Mishra A, Joseph J, et al: Recruitment of mesenchymal stem cells into prostate tumours promotes metastasis. Nat Commun 2013, 4:1795.

95. Grymula K, Tarnowski M, Wysoczynski M, Drukala J, Barr FG, Ratajczak J, et al: Overlapping and distinct role of CXCR7-SDF-1/ITAC and CXCR4-SDF-1 axes in regulating metastatic behavior of human rhabdomyosarcomas. Int J Cancer 2010, 127:2554-2568.

96. Zou W, Machelon V, Coulomb-L'Hermin A, Borvak J, Nome F, Isaeva T, et al: Stromal-derived factor- 1 in human tumors recruits and alters the function of plasmacytoid precursor dendritic cells. Nat Med 2001, 7:1339-1346.
97. Broxmeyer HE, Cooper S, Kohli L, Hangoc G, Lee Y, Mantel C, et al: Transgenic expression of stromal cell-derived factor-1/CXC chemokine ligand 12 enhances myeloid progenitor cell survival/antiapoptosis in vitro in response to growth factor withdrawal and enhances myelopoiesis in vivo. J Immuno/ 2003, 170:421-429.

98. Spiegel A, Kollet O, Peled A, Abel L, Nagler A, Bielorai B, et al: Unique SDF-1-induced activation of human precursor-B ALL cells as a result of altered CXCR4 expression and signaling. Blood 2004, 103:2900-2907.

99. Ratajczak MZ, Zuba-Surma E, Kucia M, Reca R, Wojakowski W, Ratajczak J: The pleiotropic effects of the SDF-1-CXCR4 axis in organogenesis, regeneration and tumorigenesis. Leukemia 2006, 20:1915-1924.

100. Lengyel E: Ovarian cancer development and metastasis. Am J Pathol 2010 177:1053-1064.

101. Guo L, Cui ZM, Zhang J, Huang Y: Chemokine axes CXCL12/CXCR4 and CXCL16/CXCR6 correlate with lymph node metastasis in epithelial ovarian carcinoma. Chin J Cancer 2011, 30:336-343.

102. Shen $X$, Wang $S$, Wang $H$, Liang $M$, Xiao L, Wang Z: The role of SDF-1/ CXCR4 axis in ovarian cancer metastasis. J Huazhong Univ Sci Technolog Med Sci 2009, 29:363-367.

103. Sawada K, Radjabi AR, Shinomiya N, Kistner E, Kenny H, Becker AR, Turkyilmaz MA, Salgia R, Yamada SD, Vande Woude GF, Tretiakova MS, Lengyel E: c-Met overexpression is a prognostic factor in ovarian cancer and an effective target for inhibition of peritoneal dissemination and invasion. Cancer Res 2007, 67:1670-1679.

104. Sawada K, Mitra AK, Radjabi AR, Bhaskar V, Kistner EO, Tretiakova M, Jagadeeswaran S, Montag A, Becker A, Kenny HA, Peter ME, Ramakrishnan V, Yamada SD, Lengyel E: Loss of E-cadherin promotes ovarian cancer metastasis via alpha 5-integrin, which is a therapeutic target. Cancer Res 2008, 68:2329-2339.

105. Wang D, Zhao Z, Caperell-Grant A, Yang G, Mok SC, Liu J, Bigsby RM, Xu Y: S1P differentially regulates migration of human ovarian cancer and human ovarian surface epithelial cells. Mol Cancer Ther 2008, 7:1993-2002.

106. Yuecheng $Y$, Xiaoyan $X$ : Stromal-cell derived factor-1 regulates epithelial ovarian cancer cell invasion by activating matrix metalloproteinase- 9 and matrix metalloproteinase-2. Eur J Cancer Prev 2007, 16:430-435.

107. Zhou HY, Pon YL, Wong AS: Synergistic effects of epidermal growth factor and hepatocyte growth factor on human ovarian cancer cell invasion and migration: role of extracellular signal-regulated kinase $1 / 2$ and p38 mitogen-activated protein kinase. Endocrinology 2007, 148:5195-5208.

108. Hu J, Shao S, Song Y, Zhao J, Dong Y, Gong L, Yang P: Hepatocyte growth factor induces invasion and migration of ovarian cancer cells by decreasing the expression of E-cadherin, beta-catenin, and caveolin-1. Anat Rec (Hoboken) 2010, 293:1134-1139.

109. Scharovsky OG, Mainetti LE, Rozados VR: Metronomic chemotherapy: changing the paradigm that more is better. Med Oncology 2009, 16:7-15.

doi:10.1186/1757-2215-6-95

Cite this article as: Ratajczak et al.: Induction of a tumor-metastasisreceptive microenvironment as an unwanted and underestimated side effect of treatment by chemotherapy or radiotherapy. Journal of Ovarian Research 2013 6:95.

\section{Submit your next manuscript to BioMed Central and take full advantage of:}

- Convenient online submission

- Thorough peer review

- No space constraints or color figure charges

- Immediate publication on acceptance

- Inclusion in PubMed, CAS, Scopus and Google Scholar

- Research which is freely available for redistribution 